\title{
About economic assessment of the ecological damage caused to the air basin in Russia
}

\author{
Raisa Damineva ${ }^{1, *}$ \\ ${ }^{1}$ Ufa State Petroleum Technological University (Branch in Sterlitamak), 450062, 1 Kosmonavtov str., \\ Sterlitamak, Russia
}

\begin{abstract}
The paper analyzes the condition of atmospheric air on the basis of determining the dynamics of emissions structure by types of pollutants. Types of consequences from pollution of the air basin are considered. The paper also reviews approaches toward calculations of payments for emissions of harmful substances and economic assessment of ecological damage caused by the pollution of the air basin.
\end{abstract}

\section{Introduction}

On the basis of the statistical information provided by Rosstat [1], authors conducted a short analysis of a condition of the surrounding environment of the Russian Federation from 2005 for 2015.

The greatest impact on the pollution of atmospheric air in the Russian Federation is made by the following types of economic activity:

a) Mining companies, with the share of emissions from 30.1 to $27.5 \%$. Namely, these are the companies working in the field of production of fuel and energy resources, processing productions (on which change of a share of emissions makes from 27.6 to $24.9 \%$ );

b) Processing industries, with the share of emissions from 35.5 to $34.5 \%$, including metallurgical production and production of finished metal products (on which the share of emissions makes about $23 \%$ );

c) Enterprises for production and distribution of the electric power, gas and water $(19.5 \%$ in $2005,21.2 \%$ in 2015$)$;

d) Organizations of transport and communication (on which the share of emissions makes about $10 \%$ ).

Analyzing dynamics of the structure of emissions, one may state that in the considered period (from 1992 to 2015), a decrease in specific weight of emissions of solid substances is from $19.9 \%$ to $10.5 \%$, and, respectively, an increase in specific weight of emissions of gaseous substances is from 80.1 to $89.5 \%$. Among the last, the greatest share of emissions is the sulfur dioxide emissions (decreasing in specific weight from 29.0 to $23.7 \%$ ) and carbon oxide emissions (increasing in specific weight, 24.2-27.8\%). In the considered

\footnotetext{
* Corresponding author: daminevarm@ mail.ru
} 
period, the growth of specific number of emissions of volatile organic compounds is noted (5.7 to $7.5 \%)$.

\section{Literature Review}

As is well-known [2], there are serious ecological, social, economic consequences from pollution of the nature, including the air basin. Ecological consequences of environmental pollution are caused by such level of change in quantitative and qualitative structure of air and water basins and the soil, when there is excess of opportunities of the protective mechanism of the given natural strength. It leads to negative impact of pollutants on natural objects. Ecological consequences of environmental pollution are expressed in violation of the balance which has developed in the nature in relationship in separate systems, and between them.

Social consequences environmental pollution are caused by changes in conditions of activity of the person and are defined by the degree of negative impact of pollutants on health of the population. This influence might be traced in such measurements as the change of life expectancy and the period of vigorous activity of people.

Economic consequences represent additional expenses in the following spheres: production of goods, non-productive and personal consumption, caused by negative impact of the polluted environments. Additional expenses are caused by the following reasons:

a) Acceleration of physical wear of fixed assets in the industry, transport, communication, and housing and communal services;

b) Losses of raw materials and products together with flue gases and sewage that leads to the growth of expenses on treatment facilities, to short-reception of a part of products, environmental pollution;

c) Decreases in the efficiency of rural areas, fishery, and forestry;

d) A short-reception by society of a part of net income because of increasing incidences of the population and turnover of staff;

e) Losses of recreational value of water objects that causes transfer of rest houses, resorts and sanatoria to other places.

For the purpose of compensation for damage put to surrounding natural various methodical recommendations are developed.

In the economic scholarly literature, there are two approaches by determination of economic damage from pollution of the surrounding environment. The first approach is based on accounting the local damages caused to certain spheres of the national economy. The second approach provides calculation of economic damage separately by each aspect of the environment (air, water basins, the soil).

On the basis of methodical recommendations about damage assessment from accidents on hazardous production facilities [3] the size of ecological damage is recommended to be determined on the basis of calculation of a payment for emissions/dumpings of harmful substances. Additionally, in the papers [2, 4], the methodical recommendations developed by V.I. Danilov-Danilyan are considered.

\section{Methods}

We offer not to combine a technique of defining a payment for emissions of harmful substances with a technique of assessing the ecological damage caused to the surrounding environment for the following reasons.

First, the size of damage reflects macroeconomic losses as is defined in all territory of distribution of pollution. 
Second, the economic damage reflects results of change of degree of negative impact on recipients of the pollution which has developed around a back-ground. The developed background of pollution arises owing to activity of all sources of emissions of the pollution located in this area.

Thus, the economic damage represents cumulative result of all production economic activity, which is carried out in the explored area and, therefore, cannot be compared with the size of a payment for emissions/dumpings of harmful substances.

The integrated calculation of a payment for emissions of harmful substances in the atmosphere and assessment of economic damage for the main pollutants on which the report on a form 2TP-air is formed is given in table 1.

Table 1. Payment for emissions of harmful substances and economic assessment of damage from air pollution.

\begin{tabular}{|c|c|c|c|c|c|}
\hline \multirow[b]{2}{*}{ Years } & \multirow[b]{2}{*}{$\begin{array}{l}\text { Specified lot } \\
\text { of emission }\end{array}$} & \multirow{2}{*}{$\begin{array}{l}\text { General amount of a } \\
\text { payment for } \\
\text { emissions of } \\
\text { harmful substances, } \\
\text { rubles }\end{array}$} & \multirow[b]{2}{*}{$\begin{array}{l}\text { Economic } \\
\text { assessment of } \\
\text { damage, } \\
\text { rubles }\end{array}$} & \multicolumn{2}{|c|}{ Relation } \\
\hline & & & & $\begin{array}{l}\text { Payments to } \\
\text { damage, } \\
\text { ruble/ruble. }\end{array}$ & $\begin{array}{l}\text { Payments to the } \\
\text { specified lot of } \\
\text { emission, ruble/, } \\
\text { cond. t. }\end{array}$ \\
\hline 1992 & 789081,2 & 1133944 & 53184076 & 0,021321 & 1,437044 \\
\hline 1993 & 695089,5 & 998423,3 & 46849030 & 0,021312 & 1,436395 \\
\hline 1994 & 621821,4 & 893163,1 & 41910764 & 0,021311 & 1,436366 \\
\hline 1995 & 608654,6 & 874462,3 & 41023317 & 0,021316 & 1,436714 \\
\hline 1996 & 587453,8 & 838520,1 & 39594383 & 0,021178 & 1,427381 \\
\hline 1997 & 563199,8 & 806886,8 & 37959669 & 0,021256 & 1,432683 \\
\hline 1998 & 545491,4 & 776042,2 & 36766122 & 0,021108 & 1,422648 \\
\hline 1999 & 545131,6 & 768218,5 & 36741868 & 0,020909 & 1,409235 \\
\hline 2000 & 554591,7 & 774089,9 & 37379479 & 0,020709 & 1,395783 \\
\hline 2001 & 562441 & 775834,7 & 37908521 & 0,020466 & 1,379406 \\
\hline 2002 & 587155,1 & 785066,8 & 39574256 & 0,019838 & 1,337069 \\
\hline 2003 & 596122,5 & 793065,2 & 40178659 & 0,019738 & 1,330373 \\
\hline 2004 & 630455,7 & 814601,2 & 42492715 & 0,01917 & 1,292083 \\
\hline 2005 & 621527,5 & 803862,5 & 41890956 & 0,019189 & 1,293366 \\
\hline 2006 & 619820,3 & 807149,5 & 41775888 & 0,019321 & 1,302232 \\
\hline 2007 & 623309,9 & 802567,4 & 42011089 & 0,019104 & 1,28759 \\
\hline 2008 & 602881 & 783298,7 & 40634178 & 0,019277 & 1,299259 \\
\hline 2009 & 568828,9 & 742911,7 & 38339067 & 0,019377 & 1,306037 \\
\hline 2010 & 571822,8 & 745740,2 & 38540857 & 0,019349 & 1,304146 \\
\hline 2011 & 579290,4 & 749042,6 & 39044175 & 0,019184 & 1,293035 \\
\hline 2012 & 596595,7 & 765209,3 & 40210550 & 0,01903 & 1,282626 \\
\hline 2013 & 556385,5 & 720343,5 & 37500382 & 0,019209 & 1,294684 \\
\hline 2014 & 523906,3 & 683390,1 & 35311284 & 0,019353 & 1,304413 \\
\hline 2015 & 519911,5 & 681568,6 & 35042038 & 0,01945 & 1,310932 \\
\hline
\end{tabular}

Properly, from results of the calculations given in the table, the calculated size of a payment for emissions of harmful substances in the atmosphere during the considered period covers only $2 \%$ of the size of damage caused to the air basin which has been calculated by the technique stated in work [2].

\section{Results}

On the basis of results of the calculations given in Table 1, the decrease in specific size of a payment in the considered period is noted to be 1.44 to 1.31 . The size of a payment for 
emissions of harmful substances and economic damage calculated from pollution of the air basin on the main pollutants: solid substances, sulfur dioxide, nitrogen oxides, carbon oxide, hydrocarbons, volatile organic compounds.

We consider such dynamics as a decrease in economic interest of the enterprises in realization of nature protection actions.

\section{Discussion}

First, there should be a mechanism of separate accounting of payments system for emissions offered by authors and economic assessment of damage from pollution of the surrounding environment.

Second, for the purpose of strengthening economic interests of the enterprises in carrying out environment protection of actions, it is necessary to index annually standards of a payment, so that the specific size of a payment counting on unit of the specified lot of emission of harmful substances do not decrease.

Third, for the purpose of strengthening economic interests of the enterprises in carrying out nature protection activity and in addition to the existing system of payments for emissions of harmful substances in relation to the Russian practice, we propose to develop the known economic instruments of regulation of environmental protection activity, for example, such as trade in the rights for emission, a mortgage deposit, which could expand the scope of the system of returnable deposits and "green" taxes.

\section{Conclusion}

Improving the system of the economic tools used in the Russian practice of nature protection regulation will allow to realize more successfully the known economic functions of the state, such as redistribution of resources, namely reduction of expenses from a modulation of resources.

\section{References}

1. Goskomstat of the Russian Federation, Data portal (http://www.gks.ru/).

2. R. M. Damineva, E. V. Yevtushenko, Economy of industrial environmental management (Oil and Gas Business Publishing House, Ufa, 2016)

3. Methodical recommendations about damage assessment from accidents on hazardous production facilities (RD 03-496-0) (Moscow, 2007).

4. V. I. Danilov-Danilyan, The methodical instructions by determination of the prevented ecological damage approved by the Chairman of Goskomecology of the Russian Federation (Moscow, 1999) 